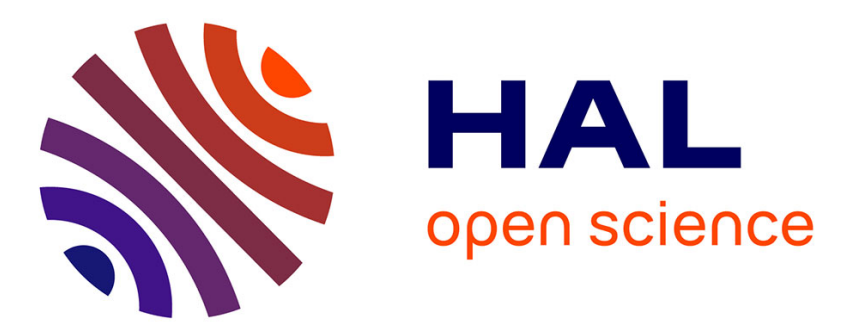

\title{
Technico-economical analysis of a hybrid wave power-air compression storage system
}

\author{
David Hernández-Torres, Laurent Bridier, Mathieu David, Philippe Lauret, \\ Thomas Ardiale
}

\section{- To cite this version:}

David Hernández-Torres, Laurent Bridier, Mathieu David, Philippe Lauret, Thomas Ardiale. Technico-economical analysis of a hybrid wave power-air compression storage system. Renewable Energy, 2015, 74, pp.708-717. 10.1016/j.renene.2014.08.070 . hal-01066899

\section{HAL Id: hal-01066899 \\ https://hal.science/hal-01066899}

Submitted on 23 Sep 2014

HAL is a multi-disciplinary open access archive for the deposit and dissemination of scientific research documents, whether they are published or not. The documents may come from teaching and research institutions in France or abroad, or from public or private research centers.
L'archive ouverte pluridisciplinaire HAL, est destinée au dépôt et à la diffusion de documents scientifiques de niveau recherche, publiés ou non, émanant des établissements d'enseignement et de recherche français ou étrangers, des laboratoires publics ou privés. 


\title{
Technico-economical analysis of a hybrid wave power- air compression storage system
}

\author{
David Hernández-Torres ${ }^{\mathrm{a}, *}$, Laurent Bridier $^{\mathrm{a}}$, Mathieu David ${ }^{\mathrm{a}, * *}$, Philippe Lauret $^{\mathrm{a}}$, Thomas Ardiale $^{\mathrm{b}}$ \\ ${ }^{a}$ Université de La Réunion, 40 Avenue de Soweto, 97410 Saint-Pierre, Reunion, France \\ ${ }^{b}$ Seawatt, 14 rue Henri Cornu, 97490 Sainte-Clotilde, Reunion, France
}

\begin{abstract}
This paper presents a technico-economical analysis of a Pelamis wave power generator coupled with a proposed air compression storage system. Ocean wave measurements and forecasts are used from a site near the city of Saint-Pierre in Réunion island, France. The insular context requires both smoothing and forecast of the output power from the wave power system. The storage system is a solution to meet this requirement. Several power network services are defined by the utility operator in order to meet different load needs. The goal is to analyze the role of the proposed storage device for each desired network service. An optimization procedure, from previous works, based on available wave energy forecast, is used to compute the optimal storage size for each service. An economical analysis shows the feasibility from the addition of the storage device, as the hybrid source power output may be economically profitable compared to a raw wave power production.
\end{abstract}

Keywords: Wave energy converter, air compression storage, network utility services, optimization, economical analysis

\section{Nomenclature}

$\begin{array}{ll}P_{\text {bid }} & \text { Guaranteed power bid }[\mathrm{kW}] \\ P_{f} & \text { Power forecast [kW] } \\ P_{\text {out }} & \text { Power output (from wave converter) }[\mathrm{kW}] \\ E_{\text {out }} & \text { Energy output }[\mathrm{kWh}] \\ E_{\text {lost }} & \text { Energy lost from } P_{\text {out }}\left[\% E_{\text {out }}\right] \\ P_{\text {sto }} & \text { Storage power }\left(P_{\text {sto }}>0 \text { charge, }\right. \\ & \left.P_{\text {sto }}<0 \text { discharge }\right)[\mathrm{kW}] \\ P_{\text {inj }} & \text { Power injected to the grid }[\mathrm{kW}] \\ P_{\text {outinj }} & \text { Injected power part from } P_{\text {out }}[\mathrm{kW}] \\ P_{\text {stoinj }} & \text { Injected power part from } P_{\text {sto }}[\mathrm{kW}] \\ P_{\text {dev }} & \text { Deviation between output power and bid }[\mathrm{kW}] \\ P_{\text {min }} * & \text { Optimally guaranteed power }[\mathrm{kW}] \\ S & \text { Useful storage capacity }[\mathrm{kWh}] \\ S O C & \text { Storage state of charge }[\mathrm{kWh}] \\ P_{c}, P_{d} & \text { Storage charge/discharge power }[\mathrm{kW}] \\ \eta_{c}, \eta_{d} & \text { Storage charge/discharge efficiency }[\%] \\ D T R & \text { Default time rate }[\%] \\ N P V & \text { Net present value }[€] \\ I R R & \text { Internal rate of return }[\%] \\ \text { FIT } & \text { Feed in tariff [€/MWh] }\end{array}$

\footnotetext{
${ }^{*}$ Corresponding author

** Principal corresponding author

Email addresses: david.hernandez-torres@univ-reunion.fr (David Hernández-Torres), laurent.bridier@univ-reunion.fr (Laurent Bridier), mathieu.david@univ-reunion.fr (Mathieu David), philippe.lauret@univ-reunion.fr (Philippe Lauret), thomas.ardiale@seawatt.re (Thomas Ardiale)
}

\section{Introduction}

Integration of renewable energy sources in island networks are of great concern because of the absence of extended, robust and interconnected electric infrastructure. Mature and well established technologies, such as wind and solar power, are stochastic by nature, thus limiting the amount of "fatal" power available from these sources [1]. Energy storage systems are a solution to cope with the intermittent character of renewable sources. They are used to efficiently smooth power output and to store exceeding production. Ocean wave energy production technologies are also somewhat stochastic, with the design of the power take off (PTO) converter and its control being a crucial stage in a wave power generation project [2].

Within this context, the Seawatt R\&D project was launched to develop a wave energy conversion farm with storage device units in the shores of Reunion island in the Indian Ocean (Lat. -21.34 Long. 55.43). The goal is to set-up an array of Pelamis P2 wave energy converters (WEC), for a total installed power of 30MW at the selected site in Saint-Pierre (Pierrefonds) [3]. The Pelamis P2 units have $750 \mathrm{~kW}$ of rated power, composed by five tube sections linked by hinged joints (180m long, $4 \mathrm{~m}$ diameter), and a conversion efficiency $\sim 70 \%$ considering both thermodynamic and electrical circuits [2]. The selected site in Reunion island is a particular challenging problem since the ratio of renewable penetration (mostly PV) is close to a $30 \%$ limitation established by the utility operator, hence the importance of a storage device design.

In this paper, an optimization methodology for sizing of the storage device is presented. The storage size of the hybrid system is optimized to comply with desired performances for several network services defined by the utility operator. The opti- 
mization method presented in [1] is used to find a suitable storage size for each service. The method, based on the day ahead power production, relies on the quality of the forecast. This has been widely studied for storage sizing with wind power $[4,5,6]$. The optimization method is based on a general basic approach using minimum search.

As a part of the Seawatt project, the storage system is composed by an on-board air compression system, that will, in fact, work as an extension of the built-in power smooth storage device delivered with the Pelamis $\mathrm{P} 2$. The additional system takes advantage of the available empty space at each structure tube. However, only static characteristics of the storage system are to be defined in this paper, as the assumptions made on the optimization method implies that the storage time constant is lower or equal to the considered time step $\Delta t$ ( $1 \mathrm{~h}$ in this study).

A final step in the methodology is to analyze the economic benefit from the addition of the storage device. For this purpose, the guidelines presented in [7] are used.

\section{Ocean data and wave converter power matrix}

Wave data measurements from a chosen site near the city of Saint-Pierre (Pierrefonds) in Reunion island, France, are used. The available data include ocean state signals as significant wave height and maximum period of waves measured from 2000-2007 and 2009.

The optimization methodology presented in this paper is based on the day ahead output power bid computed from wave height forecasts. Available wave state forecast data from WW3 models are published by the US-NAVY at http://www.usgodae.org/. These forecasts include years 2005present. For this reason, the base data set was chosen for the year 2006, for complete measured and forecast data. This is a limitation that may have an influence on the resource assessment analysis, hence the results presented in this article does not consider the inter-annual variability of wave energy. To account for inter-annual variations, it is recommended to consider at least 10 year of measured data.

The measured and forecast signals of the significant wave height and maximum period for the selected site in 2006 are shown in Figure 1. Plotted data and spectral analysis of several years data shows a clearly seasonal behavior of the ocean state with particularly higher significant height and maximum period for the austral winter season.

With the forecast data, the power output of the Pelamis wave power converter can be computed using its power matrix. The Pelamis P2 power matrix, shown in Figure 2, gives the correlation between the output power and significant height and maximum period of waves, it was developed in [3] using a regression on the simulation results obtained for various wave operating conditions using a non-linear wave to wire model of the converter. Using actual measured data and assuming an overall round trip efficiency of $\eta_{\text {round }}=73.37 \%\left(\eta_{\text {round }}=\eta_{c} * \eta_{d}\right)$, the yearly mean value of effective power production $P_{\text {out }}$ is $82.51 \mathrm{~kW}$, roughly $11 \%$ of the $750 \mathrm{~kW}$ installed capacity for each converter, with maximum peaks at $667 \mathrm{~kW}(88.93 \%$ of installed capacity) during the winter season.
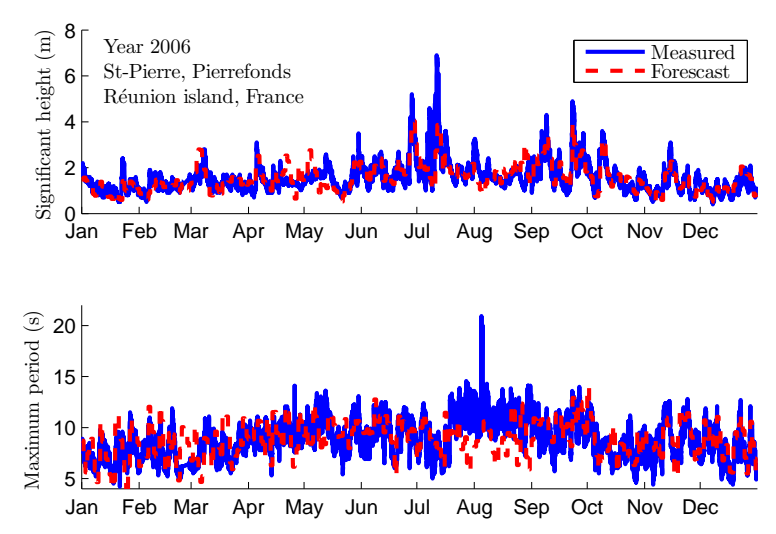

Figure 1: Significant wave height and period in Pierrefonds, year 2006.

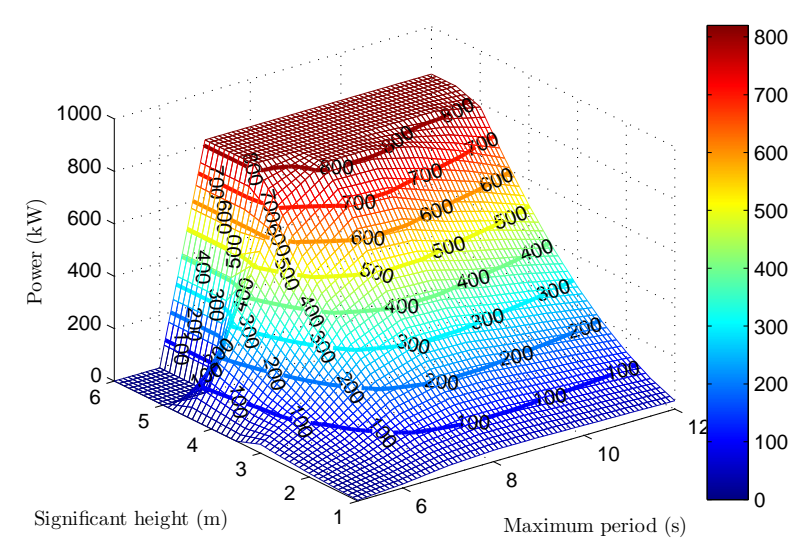

Figure 2: Pelamis power matrix.

\section{Network services}

In this paper, several power network services are analyzed. These services are defined by the utility operator in order to cope with the different load needs. System services are presented in Figure 3.

The first service S1, yields an hourly smoothed output of the day-ahead forecast power $P_{f}$. Service S2a1, comply with a bid of a yearly guaranteed constant power. Service S2a2, defines a bid of a constant power for each day of the year. Services S2b, S2c and S2d, defines bids within different time lapses for each day of the year. Specially service S2d is designed to provide a guaranteed power bid for evening peak hours. Finally services S4 and S5, defines combined bids of hourly smoothing and daily constant power with a constant power evening (1822h) service.

\section{Methodology}

\subsection{Mathematical formulation}

In this paper the storage is considered as a generic black box. The static technical characteristics of the storage system are 

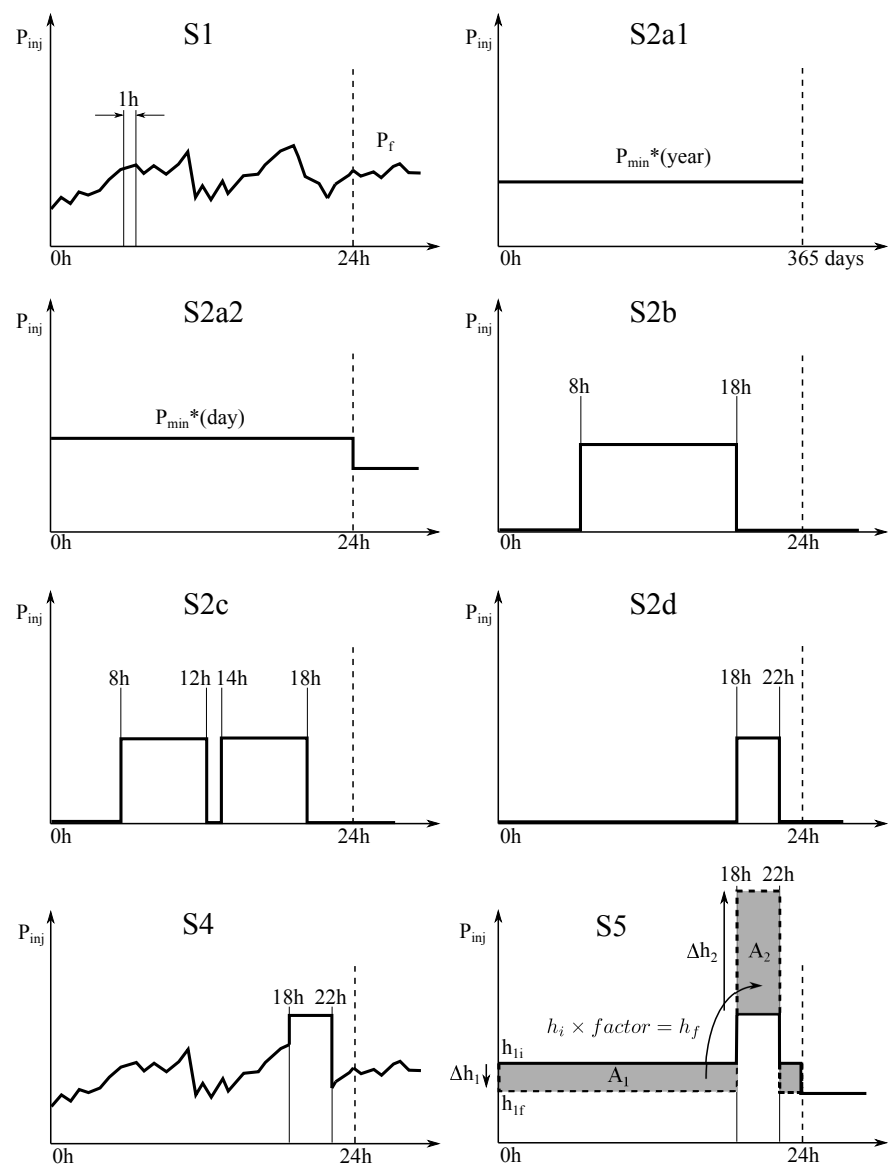

Figure 3: System services.

considered known. It is assumed that the time step of the storage device is sufficiently large compared to the systems dynamics. Transient equations are neglected and a static efficiencybased model is considered.

The default time rate (DTR) is defined as the part of the total time during which the injected power $P_{i n j}$ does not met the guaranteed power bid $P_{b i d}$ by a certain tolerance. The power bid is defined as the day-ahead announcement by the supplier to the grid operator. In a simplistic mathematical formulation the DTR can be described as:

$$
D T R \equiv P_{b i d}-P_{i n j}>\operatorname{tol}_{P} \times P_{b i d}
$$

with $\operatorname{tol}_{P}$ a given tolerance on the respecting the power bid and:

$$
P_{\text {inj }}=P_{\text {outinj }}+P_{\text {stoinj }}
$$

In theory, $P_{\text {sto }}$ should compensate the deviation $P_{\text {dev }}=P_{\text {out }}-$ $P_{\text {bid }}$. The actual storage power will however slightly differ from $P_{\text {sto }}$ because of limitations of both charge and discharge powers and the storage state of charge $S O C$.

This can be formulated as an optimization problem where we want to find:

$$
\min f(x)=\left\|x-P_{d e v}\right\|^{2}
$$

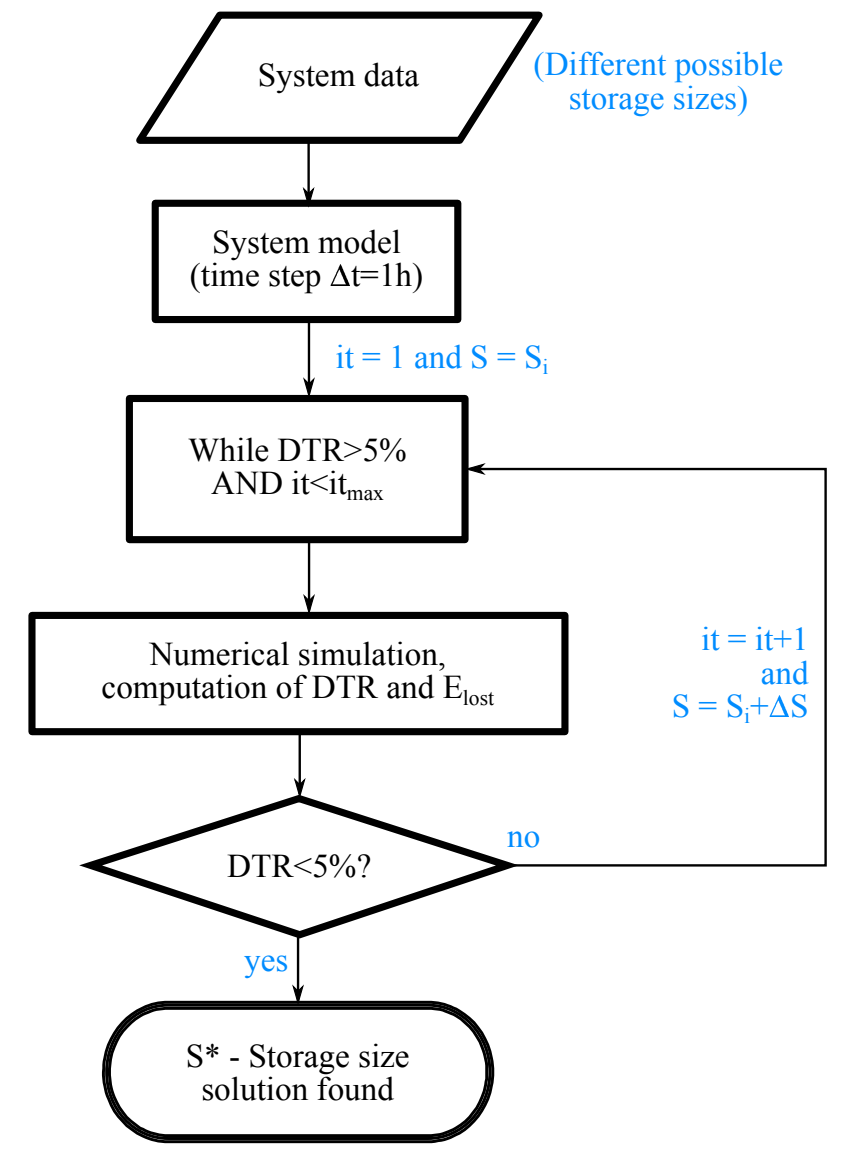

Figure 4: Flow chart of the optimization methodology.

under the power and capacity constraints:

$$
\begin{aligned}
-P_{d} & \leq x(t) \leq P_{c}, t=1, \ldots, N \\
S O C_{\text {min }} & \leq S O C(t) \leq S O C_{\text {max }}, t=1, \ldots, N
\end{aligned}
$$

with the state of charge computed by:

$$
S O C(t)=S O C(t-\Delta t)+x(t) \Delta t / S
$$

where $S$ is the storage size in $\mathrm{kWh}$ and $x(t)=P_{\text {sto }}(t)$. The optimization is defined in order to guarantee a desired default time rate:

$$
D T R<\operatorname{tol}_{D T R}
$$

with $t_{0} l_{D T R}$ generally chosen at $5 \%$, or a limitation on the percentage of the period during which the day-ahead announcement is not met. The generalized optimization process flow diagram is presented in Figure 4. In this paper the optimization is based on a minimum search on the system simulation results for many possible storage sizes that satisfies the selected constraints.

Another important design parameter is the energy loss, which is desirable to be as small as possible. As a counterpart of the DTR, a loss of energy $E_{\text {lost }}$ occurs when the power production $P_{\text {out }}$ is higher than the day-ahead announcement and the storage device has reached its full capacity. The energy excess is considered lost as it cannot be injected neither to the grid nor to the storage device. 


\subsection{Storage model}

The black-box storage model is defined by the generalized model described as follows.

If the power deviation $P_{\text {dev }} \geq 0$ (charge) then:

$$
0 \leq x(t) \leq \min \left(P_{d e v} / \eta_{c}, P_{c}\right)=\alpha_{t}, t=1, \ldots, N
$$

if $P_{d e v}<0$ (discharge) then:

$$
\beta_{t}=-\min \left(-P_{d e v} / \eta_{d}, P_{d}\right) \leq x(t)<0, t=1, \ldots, N
$$

With these definitions, the computation of the network injected powers $P_{\text {outinj }}$ and $P_{\text {stoinj }}$ is as follows:

- If $P_{d e v} \geq 0$ (charge):

$$
\begin{aligned}
& P_{\text {outinj }}=P_{\text {bid }} \\
& P_{\text {stoinj }}=0
\end{aligned}
$$

- If $P_{d e v}<0$ (discharge):

$$
\begin{aligned}
& P_{\text {outinj }}=P_{\text {out }} \\
& P_{\text {stoinj }}=P_{\text {sto }}=x(t)
\end{aligned}
$$

where the actual storage power $P_{\text {sto }}$ takes into account the charge/discharge powers and the storage capacity limitations.

A simplified schematic bloc diagram of the mathematical formulation presented is given in Figure 5.

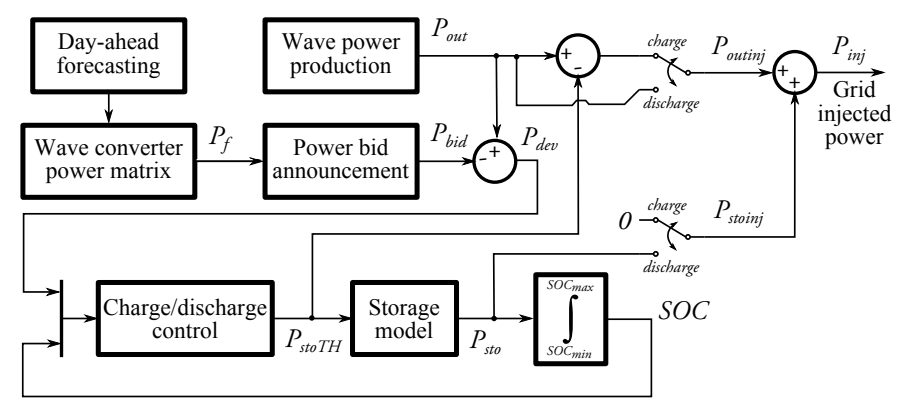

Figure 5: Modeling block diagram.

\subsection{Tolerance layer strategy}

A more specific formulation and application of the optimization method includes the use of a tolerance layer strategy. This approach is used to further reduce the storage size while respecting the services tolerances, as a contrast to the simplistic formulation presented before. The strategy is based upon the choice of a charge/discharge procedure within a defined tolerance layer. Three zones are then defined: under, inside and above the layer.

The system is said to be in a fault situation when the injected power $P_{i n j}$ is under the layer:

$$
D T R \equiv P_{i n j}<P_{b i d}-t o l
$$

For the sake of simplicity, in this study, $t o l=\operatorname{tol}_{P}=\operatorname{tol}_{D T R}$. The tolerance layer strategy is described graphically in Figure 6.
In this work the charging phase is fixed to occur until the power output equals the lower limit of the layer $\left(P_{\text {out }}=P_{\text {bid }}-\right.$ tol). In the other hand, the discharge is fixed to occur until the power output equals the upper limit of the layer $\left(P_{\text {out }}=\right.$ $\left.P_{b i d}+t o l\right)$

In the following sections, the operational strategies for each zone are defined as a function of the power output $P_{\text {out }}$ and the tolerance layer limits \pm tol.

\subsubsection{Above the layer (charge zone)}

The system is above the tolerance layer if:

$$
P_{\text {out }}>P_{\text {bid }}+\text { tol }
$$

Under this condition, the operational strategy is computed as follows. First, the maximal storage power limited by the state of charge $P_{\text {StoMAX }}$ and the "theoretical" $P_{\text {StoTH }}$ storage power are computed:

$$
\begin{gathered}
P_{\text {stoMAX }}=\left(S O C_{\text {max }}-S O C(t)\right) \times \frac{S}{\Delta t} \\
P_{\text {stoTH }}=\min \left(P_{c},\left(P_{\text {out }}-P_{\text {bid }}+t o l\right), P_{\text {stoMAX }} / \eta_{c}\right)
\end{gathered}
$$

Then the actual "physical" $P_{\text {sto }}$ power stored under the charging condition is given by:

$$
P_{\text {sto }}=\eta_{c} \times P_{\text {stoTH }}
$$

The new state of charge is computed by:

$$
S O C(t+\Delta t)=S O C(t)+P_{s t o} \times \Delta t / S
$$

Finally injected powers are respectively:

$$
\begin{aligned}
& P_{\text {outinj }}=P_{\text {out }}-P_{\text {stoTH }} \\
& P_{\text {stoinj }}=0
\end{aligned}
$$

If $P_{\text {out }}-P_{\text {sto }}>P_{\text {bid }}+$ tol then the energy loss is computed by the following condition:

$$
\begin{aligned}
E_{\text {lost }} & =\left(P_{\text {out }}-P_{\text {stoTH }}-\left(P_{\text {bid }}+t o l\right)\right) \times \Delta t \\
P_{\text {outin } j} & =P_{\text {bid }}+\text { tol }
\end{aligned}
$$

else $E_{\text {lost }}=0$.

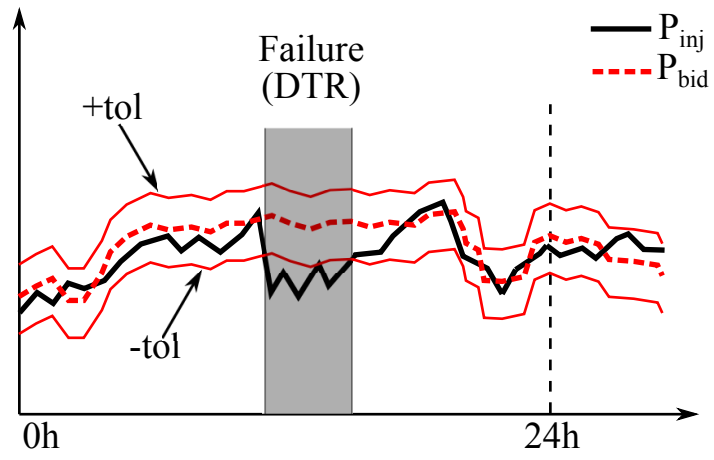

Figure 6: DTR definition for tolerance layer strategy. 


\subsubsection{Under the layer (discharge zone)}

The system is under the tolerance layer if:

$$
P_{\text {out }}<P_{\text {bid }}-\text { tol }
$$

Under this condition, the minimal storage power limited by the state of charge $P_{\text {stoMIN }}$ and the "theoretical" $P_{\text {stoTH }}$ powers are computed:

$$
\begin{gathered}
P_{\text {stoMIN }}=\left(S O C_{\text {min }}-S O C(t)\right) \times \frac{S}{\Delta t} \\
P_{\text {stoTH }}=-\min \left(P_{d},-\left(P_{\text {out }}-P_{\text {bid }}+t o l\right) / \eta_{d},-P_{\text {stoMIN }}\right)
\end{gathered}
$$

Then the actual "physical" $P_{\text {sto }}$ power discharged from the storage device is given by:

$$
P_{\text {sto }}=\eta_{d} \times P_{\text {stoTH }}
$$

However in this case the new state of charge will be computed by:

$$
S O C(t+\Delta t)=S O C(t)+P_{\text {stoTH }} \times \Delta t / S
$$

The injected power will be:

$$
\begin{aligned}
& P_{\text {outinj }}=P_{\text {out }} \\
& P_{\text {stoinj }}=P_{\text {sto }}
\end{aligned}
$$

\subsubsection{Inside the layer}

The system will be inside the tolerance layer if:

$$
P_{\text {out }} \in\left[P_{\text {bid }}-\text { tol }, P_{b i d}+t o l\right]
$$

The injected power and the state of charge are computed following the same procedure described before for operation above the layer.

\section{Results}

In this section, simulation and optimization results for the different studied services are presented.

For some services the results are obtained using a slight modification of the maximum-charge / minimum-discharge strategy, in which if the system is operating in failure (DTR) then no power is injected to the network and the production is directly used to charge the storage device.

The storage system parameters used for the simulations are given in Table 1 . The charge efficiency $\eta_{c}$ is given by the product of the compressed air reservoir efficiency assuming adiabatic cycle (95\%) and the isentropic efficiency of the hydraulic system (92\%). The discharge efficiency $\eta_{d}$ is computed with the product of the reservoir efficiency, the hydraulic turbine efficiency $(94 \%)$ and the efficiency of the electrical conversion components (94\%). All efficiencies are assumed based on typical by default values of the air compression system components.

For service $\mathbf{S 1}$ the optimization process with $t o l=20 \mathrm{~kW}$ yields an optimal storage size of $S^{*}=550 \mathrm{kWh}$. The simulation results for the month of July 2006 are presented in Figure 7. A

\begin{tabular}{cc}
\multicolumn{2}{c}{ Table 1: Storage system data } \\
\hline Parameter & Value \\
\hline$P_{c}=P_{d}$ & $500 \mathrm{~kW}$ \\
$\eta_{c}$ & $87.4 \%$ \\
$\eta_{d}$ & $83.94 \%$ \\
$S O C_{\max }$ & $100 \%$ \\
$S O C_{\min }$ & $0 \%$ \\
\hline
\end{tabular}

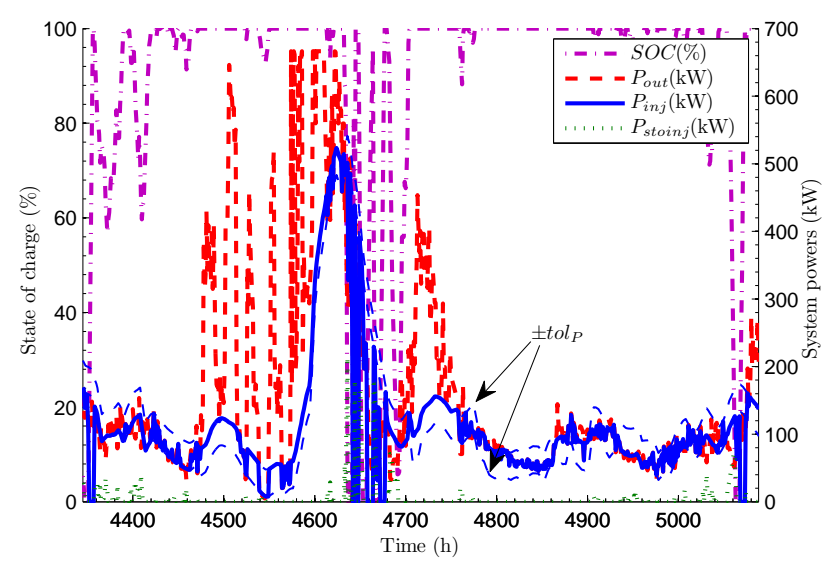

Figure 7: Simulation results for service S1 (July 2006).

total of $19.31 \%$ energy loss is obtained and the mean value of the effective network injected power is $65.6 \mathrm{~kW}$.

The service is respected by the given tolerance $(D T R<5 \%)$. Despite the relatively high loss of energy ( $\sim 20 \%)$, the storage size obtained may be a feasible candidate. Table 2 gives the results of the optimization procedure for all the considered services. The economical analysis for each service will be subsequently presented in this paper (see Section 7). The influence of the selected tolerance in the resulting storage size and the lost of energy is presented in Figure 8.

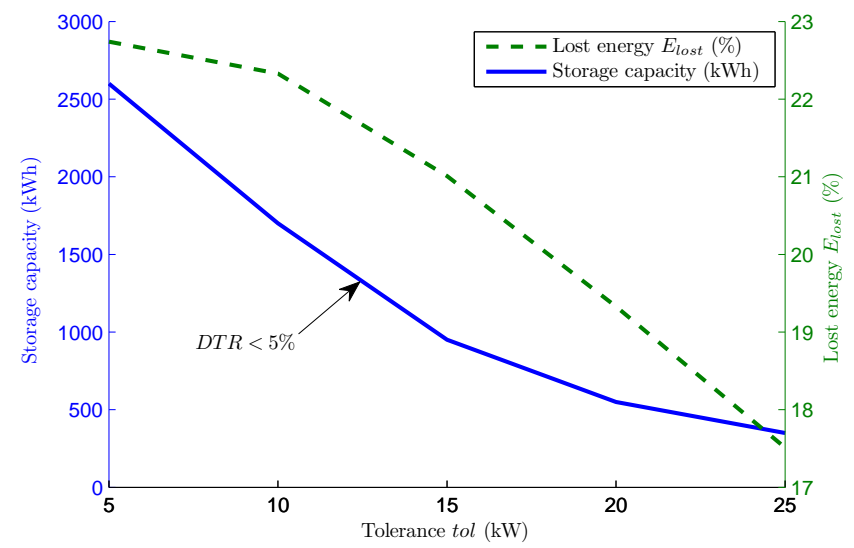

Figure 8: Optimal storage size dependence with tolerance for service S1.

Simulation results for service $\mathbf{S 2 a} \mathbf{1}$ are presented in Figure 9 
using $t o l=20 \mathrm{~kW}$ and a storage size of $S^{*}=1000 \mathrm{kWh}$. These results are obtained for a yearly $P_{\min }=50 \mathrm{~kW}$. However, the yearly mean value of the production forecast is $\bar{P}_{f}=64.56 \mathrm{~kW}$. If the yearly mean forecast is to be supplied, a hardly economically feasible storage size of $5400 \mathrm{kWh}$ will be needed. Optimization results for a small variation in range of the yearly $P_{\min }$ around $50 \mathrm{~kW}$ are given in Figure 10. In either case, energy losses are considerably higher $(35 \sim 40 \%)$ when compared with the hourly smooth service.

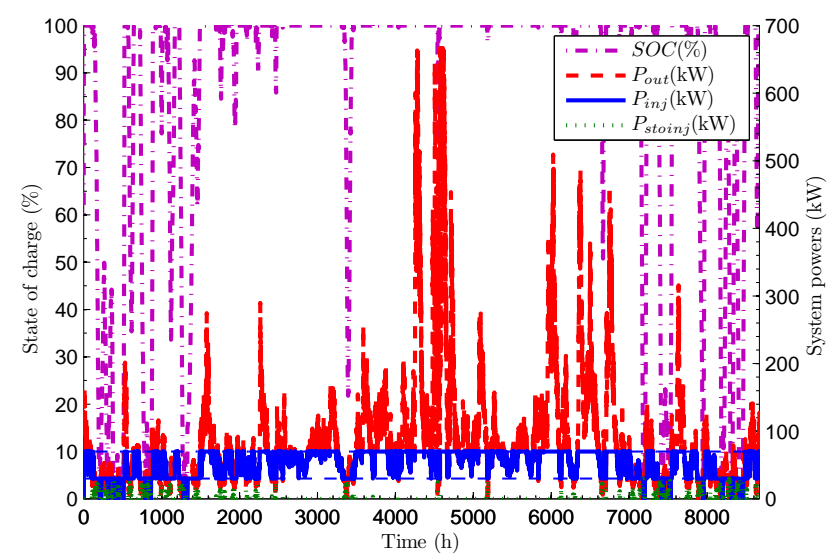

Figure 9: Simulation results for service S2a1 (year 2006).

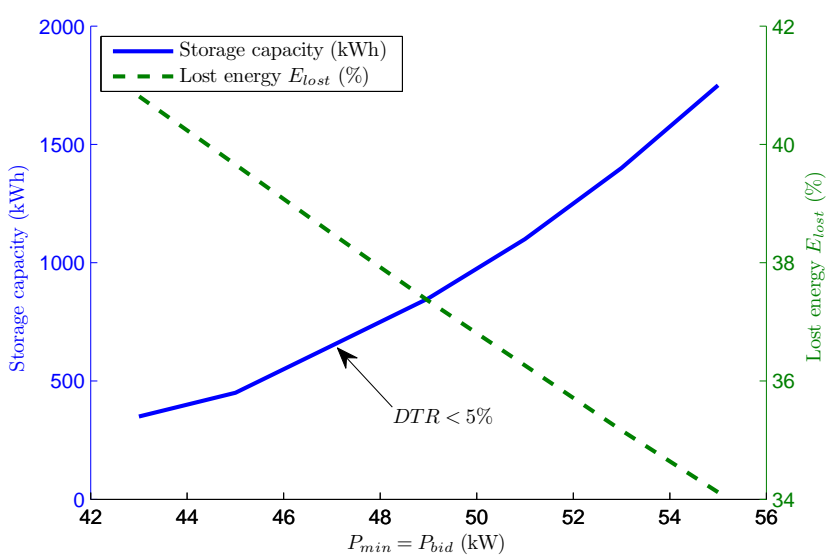

Figure 10: Optimal storage size in dependence of yearly $P_{\min }$.

The results obtained for daily-based optimization services are subsequently presented. Service S2a2 was conceived to yield a daily constant $P_{\min }$. The delivered power is considered constant by the utility operator if it lies within the tolerance layer at the given tolerance.

If the daily $P_{\min }$ value is given by the daily mean production forecast, then an optimally storage size of $600 \mathrm{kWh}$ is obtained with a $t o l=20 \mathrm{~kW}$. Results in terms of lost energy and injected power are very similar in magnitude with those obtained with service $\mathrm{S} 1$. Figure 11 shows a simulation results for the month of July 2006.

Subsequent services $\mathbf{S 2 b}, \mathbf{S 2 c}$ and $\mathbf{S 2 d}$ are particular in terms of their performance and profitability, this is because the in-

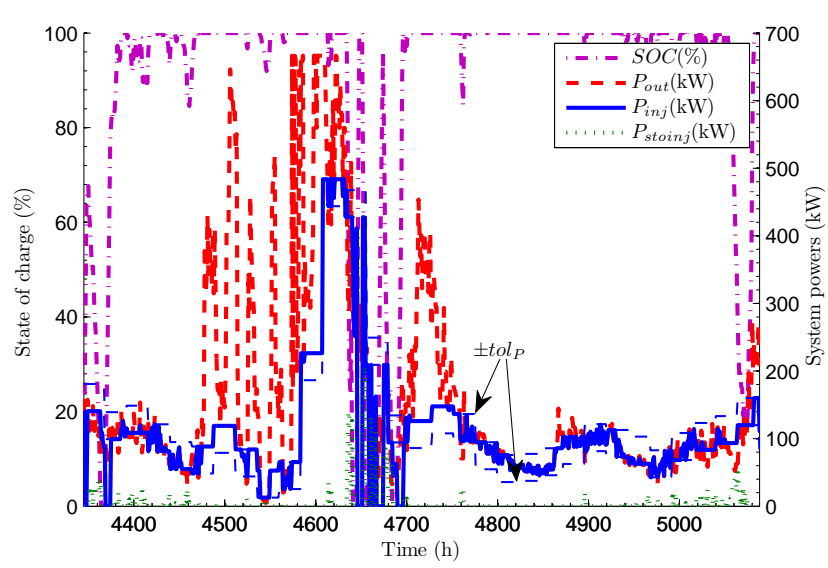

Figure 11: Simulation results for service S2a2 (July 2006).

jected power is forced to lie in between the desired delivery schedule, but this comes at the price of too high energy losses. On the other hand, resale prices may be higher for these services, as they are specifically designed to meet certain peak hour load demand. Results with these services are resumed later in this section in Table 2.

To reduce energy losses, a more interesting implementation of these services is considered as a combination with other allday injected power services ( $\mathrm{S} 1, \mathrm{~S} 2 \mathrm{a} 1$ or $\mathrm{S} 2 \mathrm{a} 2)$. This is particularly the case of services $\mathbf{S 4}$ and $\mathbf{S 5}$, that were designed as a combination of services $\mathrm{S} 1$ and $\mathrm{S} 2 \mathrm{a} 2$ respectively $(\mathrm{S} 4=\mathrm{S} 1+\mathrm{S} 2 \mathrm{~d}$ and $\mathrm{S} 5=\mathrm{S} 2 \mathrm{a} 2+\mathrm{S} 2 \mathrm{~d})$, and a constant power delivery for the evening (18-22h).

For these service an additional "factor" parameter is introduced. This parameter defines a certain amount of energy transferred from all-day service (S1 or S2a2) to the evening service (see Figure 3-S5). The "factor" term is defined by:

$$
\text { factor }=\frac{h_{f}}{h_{i}} \Rightarrow h_{i} \times \text { factor }=h_{f}
$$

where $h_{i}, h_{f}$ are initial and final values in the all-day mean injected power, then:

$$
\Delta h=h_{i}(1-\text { factor })
$$

Using equal area criterion and considering a $20 \mathrm{~h}$ base service (S1 or S2a2) and a 4 h evening service (S2d) then:

$$
\begin{aligned}
& \Delta A_{1}=\Delta h_{1} \times b_{1}=\Delta h_{1} \times 20 \\
& \Delta A_{2}=\Delta h_{2} \times b_{2}=\Delta h_{2} \times 4
\end{aligned}
$$

finally:

$$
\Delta h_{2}=5 \times h_{1 i} \times(1-\text { factor })
$$

Simulation results for service S4 are given in Figure 12. For these results the optimal storage size of $550 \mathrm{kWh}$ and a factor $=0.7$ were used. A $23.26 \%$ of energy loss is obtained and the yearly mean injected power is $61.9 \mathrm{~kW}$. However, the mean value of the constant power delivered in the evening is $111.38 \mathrm{~kW}$. As a contrast to other services, it is clear from the 
obtained results that the storage is more solicited, specially because it is needed as a support for the evening service. The use of the given factor value allows the storage to lead off the evening service with a $\sim 100 \%$ S OC for almost every day.

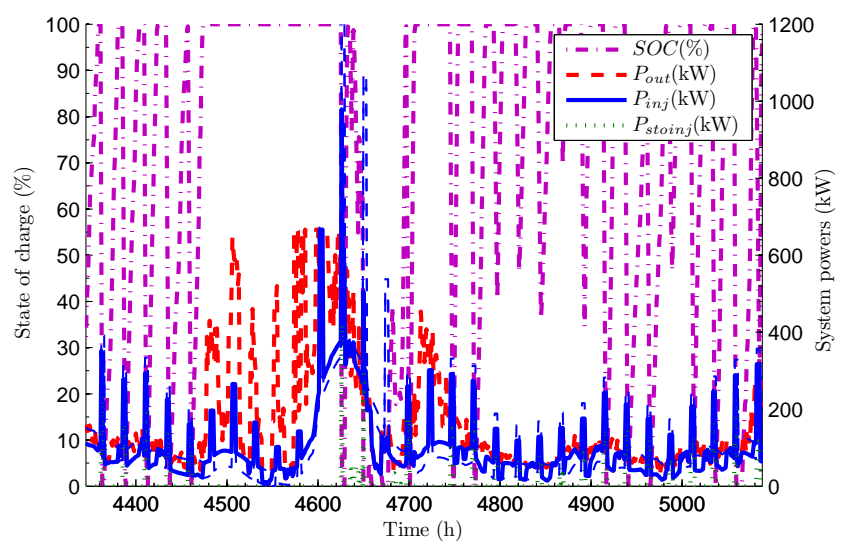

Figure 12: Simulation results for service S4 (July 2006).

Figure 13 shows the optimization results for service $\mathrm{S} 4$ and a variation in the factor value. A minimal $D T R$ value is obtained with a factor $=0.7$.
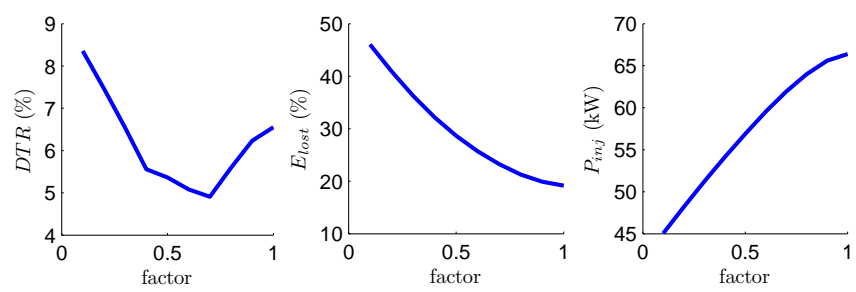

Figure 13: Optimization results for service $\mathrm{S} 4$ and a variation in factor.

A minor modification of this service ( $\mathrm{S} 4 \mathrm{~b})$ includes a $2 \mathrm{~h}$ period of time during which no power is injected to the grid and the production is entirely used to charge the storage. This time lapse is fixed at the end of the day between 22-24h.

With this strategy, a further reduced optimal size of the storage is obtained, $S^{*}=375 \mathrm{kWh}$. However, this comes at the price higher energy losses $E_{\text {lost }}=25.75 \%$ and lower yearly mean injected power $P_{i n j}=61 \mathrm{~kW}$. A supplementary economical analysis will give more justification to the choice of the final operating strategy.

Simulation and optimization results for service S5 are given respectively in Figures 14 and 15.

The obtained results are very similar to those of service S4. Again the optimal value of the factor parameter is 0.7 . The optimal storage size is $545 \mathrm{kWh}$ for service $\mathrm{S} 5 \mathrm{a}$ and $365 \mathrm{kWh}$ for service $\mathrm{S} 5 \mathrm{~b}$ (applying the same charging procedure between 22-24h).

Generally higher energy losses were obtained for services S2a1, S2b, S2c and S2d. However, these services are later implemented as combined strategies in services S4 and S5. In terms of the economical profitability services S4 and S5 may be

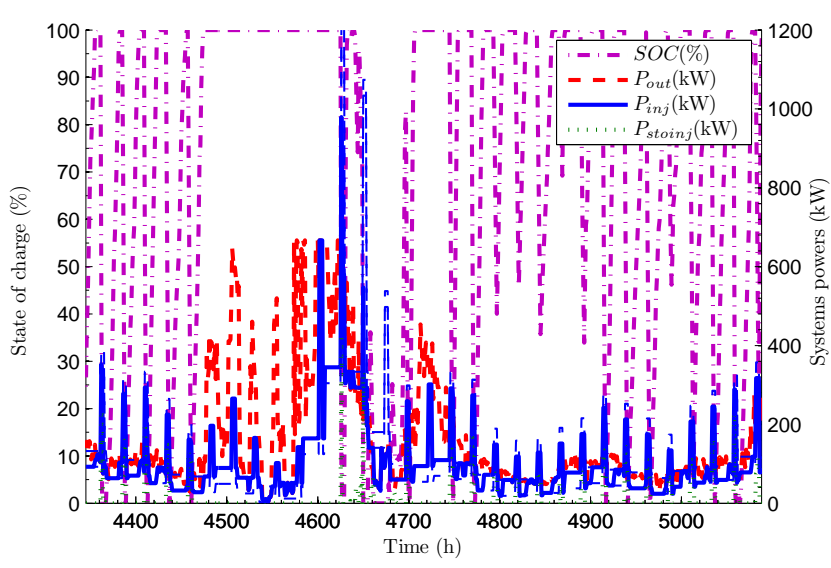

Figure 14: Simulation results for service S5 (July 2006).
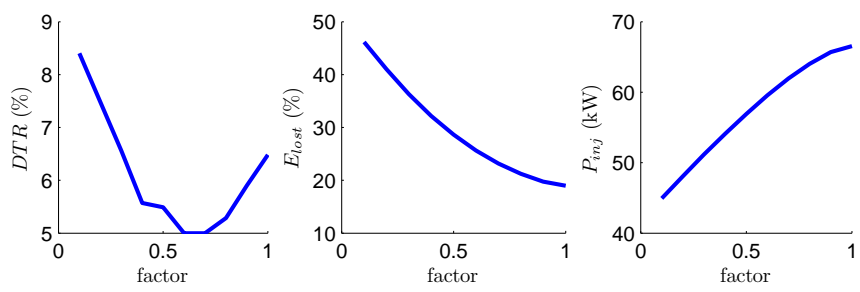

Figure 15: Optimization results for service S5 and a variation in factor.

of more interest because the evening service may have higher resale prices.

The final part of the sizing strategy deals with the economical profitability analysis. This is presented in the following section.

Table 2: Network services and storage size optimization results

\begin{tabular}{|c|c|c|c|c|c|c|}
\hline Service & $\begin{array}{c}\bar{P}_{i n j} \\
{[\mathrm{~kW}]}\end{array}$ & $\begin{array}{l}\bar{P}_{i n j T L}^{\mathrm{a}} \\
{[\mathrm{kW}]}\end{array}$ & $\begin{array}{c}E_{i n j} \\
{[\mathrm{MWh}]}\end{array}$ & $\begin{array}{l}E_{\text {lost }} \\
{[\%]}\end{array}$ & $\begin{array}{c}D T R \\
{[\%]}\end{array}$ & $\begin{array}{c}S^{*} \\
{[\mathrm{kWh}]}\end{array}$ \\
\hline $\mathrm{S} 1$ & 65.60 & - & 574.74 & 19.31 & 4.94 & 550 \\
\hline $\mathrm{S} 2 \mathrm{a} 1^{\mathrm{b}}$ & 51.76 & - & 453.50 & 36.81 & 4.80 & 1000 \\
\hline $\mathrm{S} 2 \mathrm{a} 2$ & 65.65 & - & 575.20 & 19.33 & 4.93 & 600 \\
\hline $\mathrm{S} 2 \mathrm{~b}^{\mathrm{c}}$ & 45.94 & 100.23 & 402.44 & 41.08 & 4.53 & 1000 \\
\hline $\mathrm{S} 2 \mathrm{c}^{\mathrm{d}}$ & 46.98 & 112.76 & 411.57 & 38.30 & 4.79 & 1000 \\
\hline $\mathrm{S} 2 \mathrm{~d}^{\mathrm{e}}$ & 37.92 & 182.06 & 332.25 & 48.46 & 4.95 & 1000 \\
\hline $\mathrm{S} 4 \mathrm{a}^{\mathrm{f}}$ & 61.90 & 111.38 & 542.35 & 23.26 & 4.91 & 550 \\
\hline$S 4 b^{f}$ & 61.00 & 106.93 & 534.39 & 25.75 & 4.86 & 375 \\
\hline $\mathrm{S} 5 \mathrm{a}^{\mathrm{f}}$ & 61.96 & 111.37 & 542.82 & 23.19 & 5.00 & 545 \\
\hline$S 5 b^{f}$ & 61.06 & 106.49 & 534.91 & 25.70 & 4.97 & 365 \\
\hline
\end{tabular}

a Subscript $T L$ denotes time-lapse for power delivery (for example 18-22h for service S2d).

b $P_{\text {bid }}=50 \mathrm{~kW}$, i.e., $77.45 \%$ of the yearly $\bar{P}_{\text {prev }}$.

${ }^{c}$ With $P_{b i d}=2.1 \times \bar{P}_{f}$ between $8-18 \mathrm{~h}$.

${ }^{\mathrm{d}}$ With $P_{b i d}=2.75 \times \bar{P}_{f}$ between $8-12 \mathrm{~h}$ and $14-18 \mathrm{~h}$.

e With $P_{b i d}=5.2 \times \bar{P}_{f}$ between 18-22h.

${ }^{\mathrm{f}}$ Results obtained with factor $=0.7$. 


\section{Economical analysis}

\subsection{Methodology and model assumptions}

In this section the economical analysis of the different services described above is presented. The study is based on the guidelines described in [7]. The classical cash flow and net present value $(N P V)$ methodology is considered. A similar approach was used in [8] to analyze the economical performance of a Pelamis P1 in several sites in Europe.

The NPV is computed using the equation:

$$
N P V=\sum_{n=0}^{N} \frac{C_{n}}{(1+i)^{n}}
$$

where $C_{n}$ is the total annualized cash flow for a given period $n, i$ is the annual real interest rate or the discount rate, $N$ is the project lifetime. Associated with the $N P V$ is the internal rate of return $(I R R)$, which is the rate that yields $N P V=0$ for a given period:

$$
N P V=\sum_{n=0}^{N} \frac{C_{n}}{(1+I R R)^{n}}=0
$$

The results obtained in the selected site show that the energy production is low compared to other sites worldwide. The raw produced energy by the Pelamis wave power device stands at $E_{\text {out }}=964.32 M W h$. A result somewhat comparable to a selected site in Denmark considered in the work of [8]. For a supposed feed in tariffs (FIT) of this type of energy of $150 € / \mathrm{MWh}$, a negative NPV is obtained at $-6.121 € \mathrm{M}$. In order to yield a positive NPV, a prohibitive FIT of $1.22 € / \mathrm{kWh}$ would be needed.

Given this performance, a goal was fixed in this work to evaluate the economical performance of the storage device and its contribution to operational profit for each service.

As the considered services are single cases or combinations of all-day services S1 and/or S2a2 and peak hour service S2d, the revenues from injected power to the grid will be given by:

$$
\text { Revenues }_{\text {Pelamis+Storage }}=E_{\text {inj } j_{N P H}} \times c_{1}+E_{\text {inj } j_{P H}} \times c_{2}
$$

where $c_{1}$ and $c_{2}$ are the FIT for non peak hour $(N P H)$ and peak hour $(P H)$ services, with a price condition holding as $c_{1}<c_{2}$.

The contribution of the storage device to operational profit will be computed by the difference:

$$
\text { Profit }_{\text {Storage }}=N P V_{\text {Pelamis }+ \text { Storage }}-N P V_{\text {Pelamis }}
$$

From the results obtained in the previous sections, services $\mathrm{S} 1, \mathrm{~S} 2 \mathrm{a} 2, \mathrm{~S} 4 \mathrm{a}-\mathrm{b}$ and S5a-b are retained for the economical analysis. For services $\mathrm{S} 1$ and $\mathrm{S} 2 \mathrm{a} 2$ second options strategies are considered. For $\mathrm{S} 1$, as a complement to the maximumcharge / minimum-discharge strategy $(\mathrm{S} 1+/-)$, a second exactcharge / minimum-discharge strategy (S1 0/-) is also studied. The exact-charge means that the charge zone is limited to $P_{\text {out }}>P_{\text {bid }}$. A Higher storage size is obtained with strategy $0 /-$, at the benefit of higher injected energy (see Table 5). For $\mathrm{S} 2 \mathrm{a} 2$, the results obtained with $t o l=15$ and $t o l=20 \mathrm{~kW}$ are compared. The technical analysis results, including the optimal storage size and injected energies, for each of these services are resumed in Table 3. It is assumed that the FIT for output energy injected during a DTR condition is half the value during normal power injection.

Table 3: Selected network services and injected energies

\begin{tabular}{cccccc}
\hline Service & $S^{* \mathrm{a}}$ & $E_{\text {inj }_{N P H}}^{\mathrm{a}}{ }^{\mathrm{b}}$ & $E_{\text {inj } j_{P H}}{ }^{\mathrm{a}, \mathrm{b}}$ & $E_{\text {inj }_{N P H}}{ }^{\mathrm{a}}$ & $E_{\text {in } j_{P H}}{ }^{\mathrm{a}}$ \\
\hline $\mathrm{S} 1+/-$ & 0.550 & 22.22 & - & 552.52 & - \\
$\mathrm{S} 10 /-$ & 1.200 & 17.79 & - & 569.69 & - \\
$\mathrm{S} 2 \mathrm{a} 2^{\mathrm{c}}$ & 0.600 & 19.60 & - & 555.60 & - \\
$\mathrm{S} 2 \mathrm{a} 2^{\mathrm{d}}$ & 1.050 & 17.24 & - & 545.70 & - \\
$\mathrm{S} 4 \mathrm{a}$ & 0.550 & 13.16 & 30.63 & 325.93 & 172.59 \\
$\mathrm{~S} 4 \mathrm{~b}$ & 0.375 & 10.52 & 38.83 & 328.72 & 156.27 \\
$\mathrm{~S} 5 \mathrm{a}$ & 0.545 & 14.04 & 30.92 & 325.52 & 172.28 \\
$\mathrm{~S} 5 \mathrm{~b}$ & 0.365 & 10.33 & 39.06 & 330.21 & 155.25 \\
\hline
\end{tabular}

a All units are in MWh.

b Energy injected during DTR condition.

c With tol $=20 \mathrm{~kW}$.

$\mathrm{d}$ With tol $=15 \mathrm{~kW}$.

Compressed air storage costs breakdown is presented in [9] for CAES systems. Assuming similar compressor technology and reducing the costs associated to cavern development and construction materials in CAES systems to on-board air reservoir installation, the storage device cost can be estimated between $400-700 € / \mathrm{kWh}$. Cost considerations for the worst-case scenario $(700 € / \mathrm{kWh})$ and the parameters of the economical model are resumed in Table 4. No salvage and a 20-year double-declining depreciation schedule are considered in the economical modeling.

\begin{tabular}{cc}
\multicolumn{2}{c}{ Table 4: Economical model parameters } \\
\hline Parameter & Value \\
\hline Nominal discount rate & $10 \%$ \\
Inflation rate & $2 \%$ \\
Project lifetime & 20 years \\
Income tax & $20 \%$ \\
Storage life-span & 20 years \\
Storage initial capital cost & $700 € / \mathrm{kWh}$ \\
Storage O\&M costs & $10 \%$ of capital cost \\
\hline
\end{tabular}

\subsection{Results}

For an initial comparison, the profit and the $I R R$ are computed for fixed FIT values assuming $c_{1}=300$ and $c_{2}=$ $400 € / \mathrm{MWh}$. The results are resumed in Table 5. It is clear that, even with higher injected energy and revenues, service S1 using strategy $0 /-$ is not attractive due to high storage capacity and initial capital cost. A similar result is obtained for service $\mathrm{S} 2 \mathrm{a} 2$ using a $t o l=15 \mathrm{~kW}$. Only services $\mathrm{S} 4 \mathrm{~b}$ and $\mathrm{S} 5 \mathrm{~b}$ represent interesting options in terms of profit with fixed FIT. 
Table 5: Economical analysis results for fixed FIT

\begin{tabular}{ccccc}
\hline Service & $\begin{array}{c}S^{*} \\
{[\mathrm{MWh}]}\end{array}$ & $\begin{array}{c}\text { Revenues }^{\mathrm{a}} \\
{[€]}\end{array}$ & $\begin{array}{c}\text { Profit } \\
{[€]}\end{array}$ & $\begin{array}{c}\text { IRR } \\
{[\%]}\end{array}$ \\
\hline $\mathrm{S} 1+/-$ & 0.550 & 169089 & -169090 & 2.91 \\
$\mathrm{~S} 10 /-$ & 1.200 & 173575 & -903131 & $<0$ \\
$\mathrm{~S}^{\mathrm{a} a} 2^{\mathrm{b}}$ & 0.600 & 169620 & -224074 & 0.97 \\
$\mathrm{~S} 2 \mathrm{a} 2^{\mathrm{c}}$ & 1.050 & 166296 & -783353 & $<0$ \\
$\mathrm{~S} 4 \mathrm{a}$ & 0.550 & 174912 & -122816 & 5.09 \\
$\mathrm{~S} 4 \mathrm{~b}$ & 0.375 & 170467 & 49084 & 12.53 \\
$\mathrm{~S} 5 \mathrm{a}$ & 0.545 & 174857 & -117333 & 5.29 \\
$\mathrm{~S} 5 \mathrm{~b}$ & 0.365 & 170524 & 61379 & 13.22 \\
\hline
\end{tabular}

a Yearly revenues.

b With $t o l=20 \mathrm{~kW}$.

c With $t o l=15 \mathrm{~kW}$.

Assuming FIT values variation ranges, profit and $I R R$ are presented in Figures 16 and 17 for services S1 and S2a2. Similar results are obtained for both services. Strategies S1 0/- and $\mathrm{S} 2 \mathrm{a} 2$ with $t o l=15 \mathrm{~kW}$ are again penalized due to high initial capital costs. Strategies S1 $+/-$ and S2a 2 tol $=20 \mathrm{~kW}$ begins to be interesting with FIT higher than $350 € / \mathrm{MWh}$.

Figure 18 shows the $10 \%$ line contours of the IRR for services S4a, S4b, S5a and S5b. Overall services S4b and S5b are retained as the most economically interesting options.

For both S4b and S5b, profitability is bounded to high FIT prices for $c_{2}$ and to the obtained low storage sizes. For these services interesting $I R R>10 \%$ starts at $\sim 350 € / \mathrm{MWh}$ (considering $c_{1} \sim 280 € / \mathrm{MWh}$ in the case of $\mathrm{S} 5 \mathrm{~b}$ ). A profit/IRR mapping for $c_{1} / c_{2}$ variation ranges for service $\mathrm{S} 5 \mathrm{~b}$ is presented in Figure 19. For comparison purposes, the obtained NPV value of the Pelamis with storage device for service S5b stands at $-6.0597 € \mathrm{M}$. When comparing this value with the obtained NPV for the Pelamis device alone, the contribution of the storage device to the whole system profitability can be inferred.
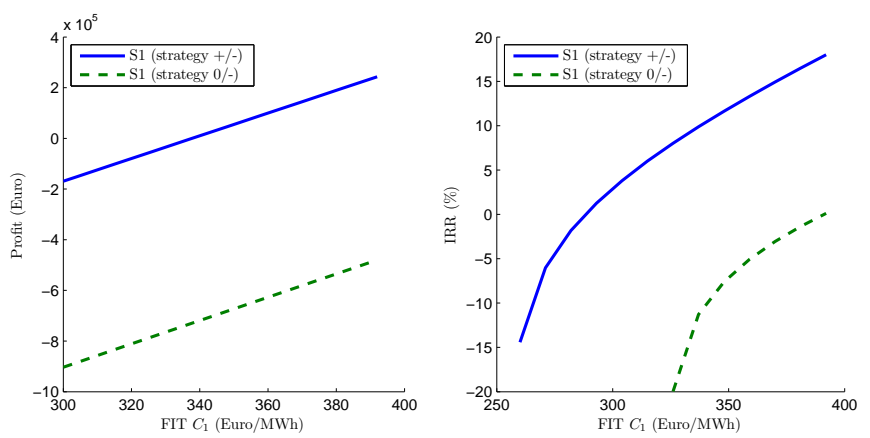

Figure 16: Economic analysis results for service S1.

\section{Conclusion}

A technico-economical optimization methodology and analysis, considering the contribution of an air compression storage
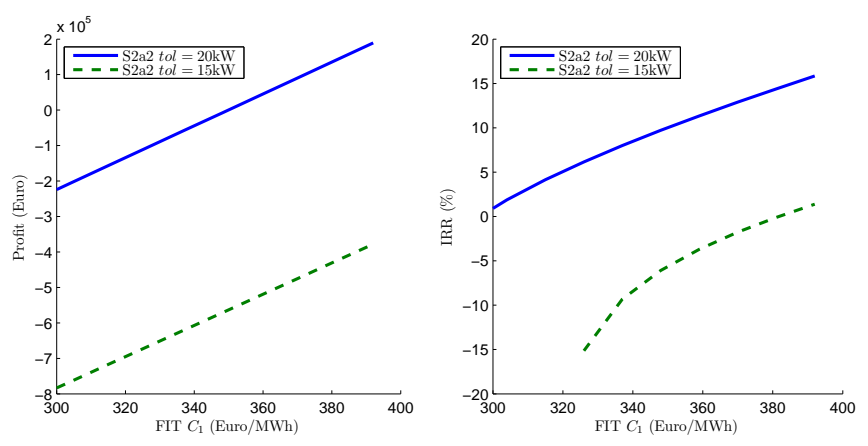

Figure 17: Economic analysis results for service S2a2.

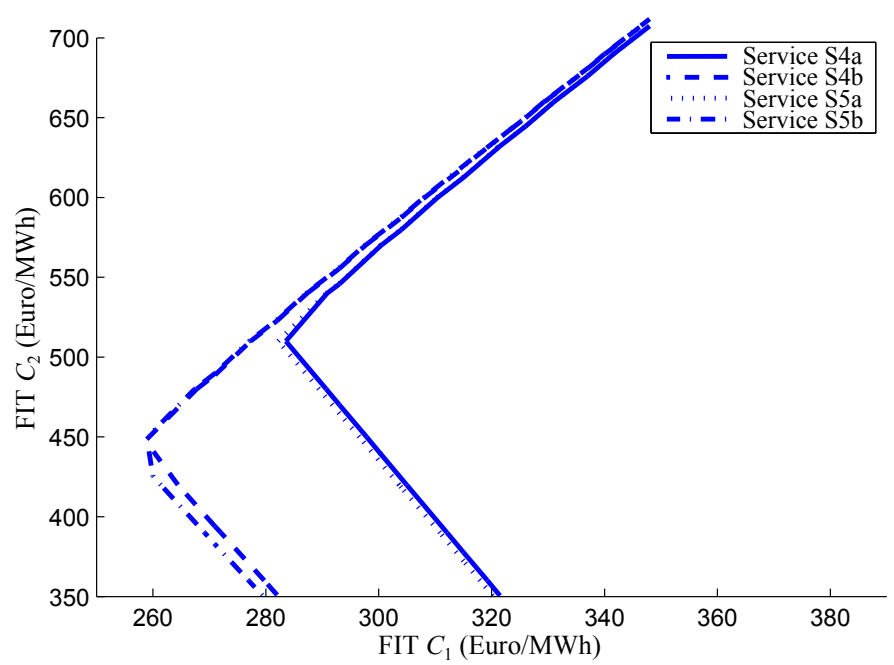

Figure 18: Contour lines for $10 \%$ IRR for services S4a, S4b, S5a and S5b.
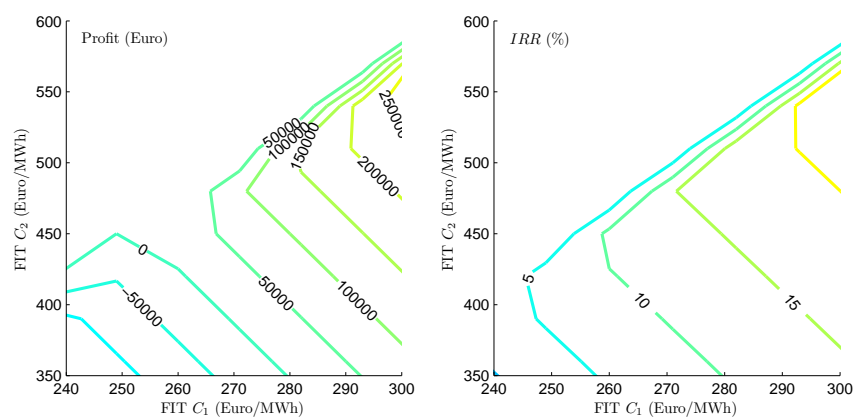

Figure 19: Profit and IRR values for service S5b.

device coupled with a wave power machine, was studied in this paper. Network services and operational strategies resulting in lower storage device size were shown to be more economically attractive while respecting the desired service performance tolerance. Specifically, services S4b and S5b were retained as the most interesting both technically and economically. It should be noted however that high FIT prices $(>350 € /$ MWh for peak hour services) are needed to guarantee profitability, this may involve some important energy policy change to stimulate wave power insertion. The obtained results shows the importance of service combination to achieve profitable energy supply to chal- 
lenge the low output power from the Pelamis PII machine (11\% capacity factor at selected site). The optimization methodology used for storage device sizing may be adapted for other types of technologies, given the black-box modeling approach. Current and future works includes the use of the sizing optimization method for wind and PV generation, the introduction of additional optimization variables within the tolerance layer strategy and the formulation of the problem as a convex optimization that may be solved using the powerful Linear Matrix Inequalities (LMI) tools.

\section{References}

[1] L. Bridier, M. David, P. Lauret, Optimal design of a storage system coupled with intermittent renewables, in: World Renewable Energy Congress WREC (to be published in Renewable Energy), Murdoch, Australia, 2013.

[2] R. Henderson, Design, simulation, and testing of a novel hydraulic power take-off system for the Pelamis wave energy converter, Renewable Energy 31 (2006) 271-283.

[3] V. Baudry, H. Mouslim, A. Babarit, Numerical estimation of the power matrix of the wave energy converter Pelamis PII, in: 13èmes journées de l'hydrodynamique, Chatou, France, 2012.

[4] M. Korpaasa, A. T. Holena, R. Hildrumb, Operation and sizing of energy storage for wind power plants in a market system, Electrical Power and Energy Systems 25 (2003) 599-606.

[5] H. Bludszuweit, J. Domínguez, Probabilistic energy storage sizing for reducing wind power forecast uncertainty, in: International Conference on Renewable Energies and Power Quality (ICREPQ'10), Granada, Spain, 2010.

[6] P. Haessig, B. Multon, H. Ben Ahmed, S. Lascaud, P. Bondon, Energy storage sizing for wind power: impact of the autocorrelation of day-ahead forecast errors, Wind Energy published online (2013) 1-18.

[7] W. Short, D. J. Packey, T. Holt, A Manual for the Economic Evaluation of Energy Efficiency and Renewable Energy Technologies, Tech. Rep. NREL/TP-462-5173, National Renewable Energy Laboratory (March 1995).

[8] M. O'Connor, T. Lewis, G. Dalton, Techno-economic performance of the Pelamis P1 and Wavestar at different ratings and various locations in Europe, Renewable Energy 50 (2013) 889-900.

[9] E. Drury, P. Denholm, R. Sioshansi, The value of compressed air energy storage in energy and reserve markets, Energy 36 (2011) 4959-4973. 